Estudios Constitucionales, Año 15, No 2, 2017, pp. 203-228

ISSN 07180105

Centro de Estudios Constitucionales de Chile Universidad de Talca

"El diálogo entre doctrina, Constitución y Cortes para el establecimiento de los contenidos mínimos de derechos sociales fundamentales. La convergencia de categorías"

Luis Alberto Petit Guerra

\title{
EL DIÁLOGO ENTRE DOCTRINA, CONSTITUCIÓN Y CORTES PARA EL ESTABLECIMIENTO DE LOS CONTENIDOS MÍNIMOS DE DERECHOS SOCIALES FUNDAMENTALES. LA CONVERGENCIA DE CATEGORÍAS (CON ESPECIAL REFERENCIA AL DERECHO AL MÍNIMO VITAL)*
}

The Dialogue BETWEen DOCTRINE, CONSTITUTION ANd COURTS FOR THE STABLISHMENT OF THE MINIMUN CONTENT OF SOCIAL FUNDAMENTAL RIGHTS. THE CONVERGENCE AMONG THE CATEGORIES (WITH SPECIAL REFERENCE TO THE VITAL MINIMUN RIGHT

\author{
Luis Alberto Petit Guerra* \\ Becario para el programa PHD Constitucional \\ Justice and Fundamental Rights (2017-2019), Universidad de Pisa, Italia. \\ luispetitguerra@hotmail.com
}

RESUMEN: En la determinación de los contenidos minimos de derechos sociales fundamentales han convergido una serie de categorias constitucionales (contenido esenciallcontenido minimo vital) para intentar dar respuestas. Aunque han nacido en el derecho público europeo (desde su doctrina y jurisprudencia) y trasladado - en virtud de esa infuencia - a varios países de ese continente y después a nuestra América; también lo es, que desde la recepción latinoamericana se han producido avances bien importantes a nivel jurisprudencial que ha permitido identificar un interesante flujo de información entre los sistemas. Se identifica un diálogo interno entre doctrina, Constitución y jurisprudencia; hasta un diálogo externo -entre Cortes- que enriquece un debate donde todo no está dicho.

\footnotetext{
- Trabajo recibido el 12 de noviembre de 2016 y aprobado el 4 de octubre de 2017.

* (i) Doctor en Derecho Constitucional, Universidad de Sevilla, España; (ii) Magíster en Derecho Constitucional, Universidad de Sevilla, España; (iii) Especialista en Derecho Procesal Constitucional, Universidad Monteávila, Venezuela; (iv) Especialista en Derecho Procesal Civil, Universidad Central de Venezuela, Venezuela; (v) Ex Juez Civil, Mercantil, Tránsito, Bancario y tutela constitucional (2010-2015); (vi) profesor de posgrado en Derecho Procesal Constitucional, Universidad Monteávila y de la Universidad Central de Venezuela (UCV); (vii) Miemb ro del Instituto Iberoamericano de Derecho Procesal Constitucional (IIDPC); (viii) Miembro del Instituto Iberoamericano de Derecho Procesal (IIDP); (ix) Miembro de la Asociación Mundial de Justicia Constitucional (AMJC); ( $x$ ) publicaciones y/o conferencias: Argentina, Bélgica, Brasil, Bolivia, Colombia, Costa Rica, Ecuador, El Vaticano, Espańa, Italia, México, Panamá, Perú, Uruguay, Venezuela.
} 
ABSTRACT: Establishing the minimum content of fundamental social rights, a series of constitutional categories (essential content Iminimum vital content) have converged to try to provide answers. Wich were certainly born by the influence of the European public law (from its doctrine and jurisprudence) and were transferred to several countries of that continent and soon to America; it is also true that the Latin American reception has achieved some important advances at jurisprudential level that has allowed to identify an interesting flow of information between the systems. An internal dialogue between doctrine, Constitution and jurisprudence is identified; to an external dialogue-between Courts-that enriches a debate but where not everything has been said.

PALABRAS CLAVE: Contenido de los derechos sociales minimos. Contenido esencial. Derecho al minimo vital. Diálogo doctrina y jurisprudencia

KEYWORDS: Content of minimum social rights. Essential content. Right to the vital minimum. Dialogue doctrine and jurisprudence.

\section{Introito. De las dificultades DEL COMPARATIVISMO A SU UTILIDAD PRÁCTICA}

Si bien no toda comparación es posible, en el sentido que se pueda transportar en forma automática determinadas teorías y categorías de un sistema jurídico a otro, en el caso del material que rodea la temática de los mecanismos de determinación de los contenidos mínimos en derechos sociales fundamentales; esta comunicación sistémica ha sido posible. Las necesidades de aquí y allá, en proporción a sus distintas dificultades, han creado -voluntaria o involuntariamente- una interesante comunicación de sistemas, con notable influencia que se consolida para impactar, en unos, con la recepción constitucional de algunas categorías (contenido esencial); en otros, con el desarrollo jurisprudencial de otras (derecho al mínimo vital para ciertos derechos sociales), e incluso, con la formulación legal (derecho al mínimo vital sólo en forma de pensiones).

En buena medida, la jurisprudencia ha permitido materializar tal "diálogo" que apunta en dos direcciones: en el plano interno de algunos países, la relación doctrina-legislación-jurisprudencia; o, doctrina-constitución-jurisprudencia; en el plano externo con la traslación de las instituciones (a suerte de ósmosis de sistemas); la comunicación se centra entre la doctrina y la jurisprudencia; donde el papel de las cortes ha sido primordial. Sin desconocer las dificultades que apuntan cierta comparación, en especial respecto a las diferencias conceptuales de instituciones y sistemas, asumimos tal desafío, sobre todo, cuando siguiendo a G. Tisseau, observamos con él que la realidad práctica supera el marco conceptual que los operadores han previsto ${ }^{1}$. El tránsito de las ideas, sistemas, formas y mecanismos

1 Tisseau (2014), p. 22. 
es innegable. El uso del derecho constitucional comparado en el razonamiento jurídico constitucional es innegable, pese algunas objeciones (con A. Scalia, C. Thomas, CF. Rosenkrantz), y otras preferencias (con G. Zagrebelsky, A. Barak²). Nos inclinamos obviamente por el sentido práctico que deriva de tal razonamiento comparado, su utilidad y colaboración en un mundo globalizado que, guardando sus diferencias, encuentra cada vez más problemas comunes.

Debido a esas relaciones y transmisión de información entre uno y otro sistema; con motivo a los cambios (actualizaciones) de los principios de legalidad, separación de poderes y democracia, los distintos sistemas van encontrando puntos en común como una magistratura cada vez más activa. Efectivamente, como explica el profesor Sagüés, el desempeño de la magistratura constitucional como agente convalidante o promotor de cambios sociales es cada vez más frecuente debido a una intensa motorización de la Constitución, que llevaría - dice-a una gimnasia procesal constitucional cada vez más intensa ${ }^{3}$.

Dadas esas conexiones y sin que pueda obviarse tampoco las complicadas argumentaciones en torno a la mejor forma de concebir los contenidos mínimos de derechos (temas que siguen sin cerrarse en la doctrina constitucional), en este artículo aludiremos brevemente a dos de los desarrollos jurisprudenciales de estas categorías. Estas categorías se encuentran -y complementan- en contextos relacionables pero diferentes: El "contenido esencial" (preferiblemente para controlar el accionar legislativo) y el "derecho al mínimo vital o existencial" (preferiblemente para controlar la omisión legislativa). Con problemas singulares y otros comunes nada menores, logran relacionarse en una interesante interacción entre la doctrina que le dio vida y una jurisprudencia como un actor más para su comprensión.

\section{De la CATEGoría del CONTENIDO ESENCIAL DE LOS DERECHOS FUNDAMENTALES. UN DIÁLOGO ENTRE "DOCTRINA, CONSTITUCIÓN Y JURISPRUDENCIA"}

Partiendo de la base que todo derecho tiene sus contenidos (que les son propios), la discusión es mayor en materia de los derechos sociales fundamentales, desde cuya perspectiva se escriben estas líneas. Porque si todos los derechos tienen por lógica contenidos explícitos e implícitos -o hay maneras de determinarlos-, también existirán límites internos y límites externos; siendo respecto de los pri-

2 Lopez Ulla (2014), pp. 358-362.

3 SAGỨS (2017), p. 218. 
meros (base mínima) donde son evidentes las aportaciones de la teoría del contenido esencial que puede encuadrarse dentro de aquellas que llamamos de los contenidos implícitos de los derechos constitucionales. Es decir, son contenidos constitucionales (abstractos) que "deduce" el legislador cuando desarrolla sus textos legislativos e imagina su núcleo mínimo (o base); el cual también identifica la jurisprudencia en protección de su núcleo (abstracto) al momento de juzgar aquellos productos normativos.

Se trata de una categoría que sólo funciona frente a las leyes ya "creadas" por el legislador, evitando que la política "vaciée" de los contenidos que, paradójicamente, se dicen constitucionales, pero sólo lo están en forma implícita; requiriéndose, por tanto, de un complejo trabajo argumental (interpretativo) para analizar hasta dónde determinada intervención/accionar del legislador, "afectó" - o no- el núcleo esencial de ciertos derechos en juego. Pero no obstante tal complejidad, el éxito de tal categoría parece indiscutible. Para la teoría dominante, el contenido esencial se tiene como (verdadero) "parámetro" para el establecimiento de los contenidos de los derechos sociales ${ }^{4}$, debido probablemente a la enorme influencia promovida por la doctrina en deferencia al Poder Legislativo, que es lo que llama Carbonell la capacidad legitimadora del Poder Legislativo en esas órdenes y funciones 5 .

Para comprender mejor la naturaleza de esta figura, que tiene su origen en Alemania, es interesante que sea probable que exista alguna orientación (previa) -según Lothar-en un país no europeo, al referirse a la influencia que dice encontrar "por el límite a las limitaciones de los derechos fundamentales del artículo 28 de la Constitución argentina (1853)". A pesar de tal relación, este mismo autor - contradiciendo a Stern 6 -, niega que ese mismo precepto de dicha Constitución contenga en sí mismo una verdadera garantía del contenido esencial al modo alemán; siguiendo la tesis de otros -como Dreier-, que niegan expresamente que haya sido inspiración al actual artículo 19.2. alemán 7 .

Desde el punto de vista histórico constitucional (como garantía institucional) y bajo la vigencia de Weimar, fueron las Constituciones de algunos Estados federados las que plasmaron esos primeros pasos en la consagración del contenido esencial de los derechos fundamentales hasta su regulación posterior en la propia Ley

4 Abramovich y Courtis (2006), p. 31.

5 Carbonell (2007), pp. 77-78.

6 STERN (1998), pp. 261-277.

7 Löthar (2009), p. 166. 
Fundamental en su artículo $19.2^{8}$. En concordancia con lo que se viene explicando, el "precedente y modelo de garantía del contenido esencial del art.19.2. LFP puede citarse el art. 63.1 de la Constitución de Hessen (1946), de conformidad con el cual 'el derecho fundamental en cuanto a tal' debe permanecer inalterado". Más adelante, en presencia de la Ley Fundamental de 1949, se constata que su artículo 19.2. establece: "En ningún caso un derecho fundamental puede ser afectado en su contenido esencial"; el cual es auspiciado desde luego de una rica contribución jurisprudencial conjunta del Tribunal Administrativo Federal, del Tribunal Supremo Federal y del Tribunal Constitucional Federal ${ }^{10}$. En concreto, dicha teoría parte del supuesto que cada derecho fundamental tendría un núcleo esencial que no podría ser afectado por el legislador en forma alguna; es decir, que existan "los elementos mínimos que hacen al Derecho reconocible11". En el caso del ordenamiento jurídico alemán, el contenido esencial es una garantía institucional más de las que contempla la Ley Fundamental ${ }^{12}$.

La influencia que ha tenido dicha categoría alemana en otros sistemas es evidente. Ese éxito se debe no sólo por los comentarios en su favor por buena parte de la doctrina en cada uno de estos países que se citan enseguida, sino principalmente por la recepción del contenido esencial en sus diversas Cartas Políticas; si revisamos la lista que trae Von Bernstorff ${ }^{13}$ y completan Nogueira Alcalá ${ }^{14}$, Varas y Mohor ${ }^{15}$ (agregando el caso de Chile). Igualmente, esta figura aparece recogida en la Carta de Derechos Fundamentales de la Unión Europea

8 LÓTHAR (2009), pp. 280-281.

9 Lóthar (2009), p. 171.

10 Casal Hernandez (2010), p. 281.

11 Obando Blanco (2002), p. 112.

12 Cruz Villalón (1989), p. 61.

13 (i) Constitución de Portugal (art. 18.3); (ii) Constitución de Suiza (art. 36); (iii) Constitución de Polonia (art. 30.3); (iv) Constitución de Rumania (art. 49.2); (v) Constitución de Eslovaquia (art. 13.4); (vi) Carta de Derechos Fundamentales de la República Checa (art. 4.4); (vii) Constitución de Hungría (art. 8.2.), (viii) Constitución de Turquía (art.13); (ix) Constitución de Albania (art. 17.2); (x) Constitución de Estonia (art. 11.2); (xi) Constitución de Kirguistán (art. 17.2); (xii) Constitución de Moldavia (art. 54.2); (xiii) Constitución Federal Argentina (art. 28); (xiv) Ley Fundamental de Alemania (art. 19.2), y (xv) Constitución del Reino de España (art. 53.1). Cfr., Von Bernstorff (2011), p. 159.

14 Nogueira (2003), p. 108.

15 VARAS Y MOHOR (1997), pp. 157-166. 
(art.17) ${ }^{16}$; así como también en el Pacto de los Derechos Civiles y Políticos (art. 5.1 $)^{17}$. Se trata, pues, de una figura de amplia aceptación y reconocimiento. De consiguiente, el hecho de que ciertos países no hayan receptado en sus Constituciones -por ej., los casos de Costa Rica ${ }^{18}$, Perú ${ }^{19}$ o Venezuela ${ }^{20}$, no quiere implicar en modo alguno la falta de recepción de esta categoría en su práctica judicial. La importancia que tiene la utilidad práctica de este instituto (frente o para evitar los abusos del legislador); llega al punto de ser entendido como "el núcleo de la articulación normativa entre Constitución, legislación y jurisdicción ${ }^{21}$ ”; que, como se resalta, se ha debido primero al impulso desde la doctrina del derecho público intercontinental.

Ahora bien, sin restar su importancia, se evidencia que este diálogo en lo interno de cada país (nos referimos a las relaciones entre doctrina, constitución y jurisprudencia) tiene también sus áreas complejas, que se resumen en (i) la indeterminación de lo que sería contenido esencial en cada derecho; (ii) la (problemática) sobre la coexistencia en su interior de las distintas teorías (relativa y absoluta) para explicar sus desarrollos, (iii) el tratamiento como concepto jurídico indeterminado; (iv) que no es aplicable frente al complicado tema de las omisiones legislativas); y por último, (v) que dicha categoría sólo es aplicable para "descifrar" cuál sería el núcleo -o contenido esencial- frente a los derechos fundamentales; dejando por fuera a buena parte de otros derechos.

\section{Del DERECho Fundamental a Un Mínimo VITAL o EXISTENCIAL. UN DIÁLOGO ENTRE "DOCTRINA, JURISPRUDENCIA Y LEGISLADOR"}

Si el "contenido esencial" supone cierta racionalidad para determinar si ciertas acciones (intervenciones) legislativas han afectado - o no- el núcleo esencial de cada derecho; surge la idea (también impulsada por la teoría) de que algunas omisiones legislativas deberían tener una consecuencia "mayor" a que sólo sean declaradas por la justicia constitucional (en los sistemas donde existan). Es decir, no basta

\footnotetext{
16 LOTHAR (2009), p. 167.

17 VON BERNSTORFF (2011), p. 157.

18 Sala Constitucional, Corte Suprema de Justicia (Costa Rica), (1999).

19 Tribunal Constitucional (Perú), (2012).

20 Sala Político Administrativa, Corte Suprema de Justicia (Venezuela), (1997).

21 Balaguer Callejón (2001), p. 96.
} 
la declaración de la omisión por parte del órgano jurisdiccional, sino que se prefiere una consecuencia adicional: darle operatividad al carácter normativo de la Constitución conforme las líneas que siguen.

Se trata de una categoría no menos compleja que la anterior del contenido esencial. Para el "derecho al mínimo vital" - como enseña Carmona- no existe una única definición, como tampoco es pacífica su propia denominación ${ }^{22}$, al coexistir con otras instituciones relacionables, pero que son tratadas en forma diferenciada por alguna doctrina ("mínimos sociales", "mínimo de subsistencia", "mínimo vital", "mínimo existencial23"). En cualquier caso, preferimos homologar (más allá de la semántica) las categorías del mínimo existencial como el minimo vital, siguiendo a buena parte de la jurisprudencia y doctrina revisada. Pero a pesar de tal introducción, se está en presencia de una importante creación doctrinal que transformará la dinámica de las relaciones del poder; produciendo una verdadera revolución en el campo de la teoría política; y principalmente en el campo de los derechos fundamentales.

En la justificación de estos derechos vitales/existenciales se busca darle "contenido" a la fórmula "Estado social de derecho"; en conjunto, principalmente, con la "dignidad humana 24 " y otros casos con la "igualdad material25". Es un nuevo diálogo entre "doctrina, jurisprudencia y legislador", porque si el contenido esencial aplica para establecer si determinadas actuaciones legislativas estaban conformes a los contenidos constitucionales (implícitos); en el caso del derecho al mínimo vital, se va más allá, cuando partiendo también de contenidos constitucionales (expresos e implícitos), es la jurisprudencia quien (a falta de actuaciones políticas) "crea" una categoría como derecho prestacional directamente exigible, para implicar después al legislador y al gobierno en su ejecución (mediante sentencias que impactan directamente en las políticas públicas). Esta categoría, sin embargo, no es exclusiva en materia de omisiones (principalmente), pues también es aplicable frente a determinadas actuaciones legislativas (cuando son impugnadas) ante la jurisdicción constitucional.

Para comprender esas justificaciones, merece revisar brevemente sus antecedentes, ya que con la Ley Fundamental de Alemania (1949), no obstante de no poseer un listado expreso de derechos sociales, existía cierta convergencia doctrinal

\footnotetext{
22 Carmona Cuenca (2012), p. 63.

23 SARLET (2015), p. 615.

24 De Barcellos (2008), p. 198.

25 Cossio díaz (1989), p. 46.
} 
acerca de la necesidad de que el Estado debería garantizar a los ciudadanos un "mínimo social"26. En este tópico serán relevantes varios trabajos, entre otros, principalmente de Otto Bachof, quien a decir del profesor Sarlet, sería "uno de los primeros en sustentar la posibilidad del reconocimiento de un derecho subjetivo a la garantía positiva de los recursos mínimos para una existencia digna ${ }^{27 ”}$.

Entonces, ¿qué se entiende como minimo vital? Lo que responde Arango lo indica con mejor precisión: "Una persona tiene un derecho fundamental a un mínimo social para satisfacer sus necesidades básicas, si pese a su situación de urgencia el Estado omite actuar, de forma que lesiona sin justificación constitucional a la persona ${ }^{28}$ ". Debe subrayarse acá que se refiere a la "omisión" estatal para comprender su diferencia con el contenido esencial (aplicable sólo en cuanto acciones legislativas); sin embargo, también es viable -como se verá- aplicar el derecho vital frente a ciertas acciones legislativas (injustificables, o incompletas).

Este derecho "evolucionado" que se consigue mediante una interpretación sistémica del texto constitucional o Ley Fundamental (LF) desde el "principio" del "Estado social" (art. 20 LF) en conjunto con el valor "dignidad" (art. 1 LF), asume la existencia de unos servicios que por básicos deben ser otorgados por el Estado. Si bien, como dice Arango, "tal reconocimiento [del mínimo vital jurisprudencial] contravenga la relación ideal [que sea en el legislador democrático donde se regulen] ${ }^{29}$ ", paradójicamente, fue reglamentado tiempo después por el propio legislador alemán en el ámbito de la asistencia social ${ }^{30}$, evidenciando la madurez de las instituciones en virtud de un verdadero diálogo. Dentro de los derechos relacionados a este "mínimo vital" se proyectaban, entre otros, alimentos, calzado, vestido, educación, ayuda sanitaria, etc., de allí que -ahora sí-corresponda al legislador la tarea de determinar la cuantía de cada una de esas prestaciones condenadas por los tribunales. Todo un debate -según hemos afirmado en otro lado- en el sistema de fuentes ${ }^{31}$.

Es así como se entiende la interacción del circuito entre poder jurisdicción y poder legislativo. Los tribunales crean el derecho "definitivo" a un mínimo vital

\footnotetext{
26 Wunder Hachem (2014), p. 100.

27 SARLET (2015), p. 617.

28 ARango (2002), p. 114.

29 ARANGo (2005), p. 153.

30 SARIET (2015), p. 617.

31 Petit Guerra (2012), pp. 531-549.
} 
mediante un complejo proceso argumentativo ${ }^{32}$; señalando algunas de las líneas maestras (para el cumplimiento de determinados derechos vitales o existenciales); para que luego sea el Poder Legislativo, y teniendo en cuenta el carácter voluble y cambiante del mínimo vital33, el que establezca los mecanismos y formas para su materialización), tomando las "decisiones políticas en el ámbito de un marco de referencia constitucional 34 ". Se comprende ahora por qué, según Cossio, "los derechos sociales se resuelven en prestaciones a cargo del Estado encaminadas a satisfacer los llamados mínimos vitales 35 ".

En términos más completos dice Wunder Hachem:

"El derecho fundamental al mínimo existencial es compuesto por partes de derechos económicos y sociales necesarias a proporcionar a su titular unas condiciones materiales de existencia mínimamente digna. Él es un minus en relación a los derechos sociales, que son provistos de un contenido más amplio, que abarca otros deberes -no sólo de prestación, sino también de abstención- que sobrepasan la circunscripción del mínimo existencial36".

Desde esa perspectiva, existiría alguna relación lineal entre derechos económicos y sociales con el mínimo vital; aunque para otros - por ej., Bernal Pulido ${ }^{37}$-, estos derechos no tienen como única y exclusiva función la satisfacción del mínimo existencial, afirmación con la que vamos a coincidir: No necesariamente todo derecho social tenga previsto un mínimo vital.

A esta altura del ensayo es posible resumir parte de las tendencias que persiguen el mismo objetivo (para el reconocimiento de un derecho al mínimo vital): (i) Una posición maximalista del "mínimo existencial definitivo", que parte de la idea de lo que debe proveerse siempre -sin excusas de ningún tipo-; (ii) una posición minimalista o "mínimo existencial prima facie", que encuentra soporte a su vez en tres tendencias: a) El grupo que asume las dificultades que son consecuencia de los costos financieros para la materialización de este tipo de derechos prestacionales, entendiendo que no debería afectarse el criterio de elección del

\footnotetext{
32 Arango (2005), p. 211.

33 De Marco (2011), p. 249.

34 Tenorio (2012), pp. 281-282.

35 Cossio díaz (1989), p. 46.

36 Wunder Hachem (2014), p. 114.

37 Bernal Pulido (2008), p. 149.
} 
legislador en esta materia ${ }^{38}$; b) aquellos que además de la existencia de los costes (operativos), condiciona aquellos derechos a la existencia de ciertas normas organizativas y procedimentales (por ej., la construcción de escuelas en el caso del derecho a la educación ${ }^{39}$ ); c) aquellos que encuadran el derecho al mínimo existencial desde las categorias de principios (que dichos derechos no son definitivos en la forma que lidera Robert Alexy ${ }^{40}$ ).

Nuestra preferencia sigue al tercer grupo o tendencia. De consiguiente, el llamado "mínimo existencial definitivo" debería ir más allá del procedimiento racional (ponderativo o de proporcionalidad tipo alexyano que sólo descansa en la posición del legislativo ${ }^{41}$ ); esto es, que más bien puede (y debe) ser proveído por los tribunales. Por ende, evitando caer en el juego ponderativo (tipo Alexy) que plantea la teoría de los derechos fundamentales por principios que guían al legislador ${ }^{42}$; estamos convencidos con Wunder, "el mínimo existencial ya es el producto de una ponderación previamente operada por el constituyente ${ }^{43 "}$. Es decir, este tipo de derechos (creados por los tribunales) operarían en una especial forma de ponderación que ya constaría desde los contenidos del propio constituyente (por ejemplo, Estado social de derecho, dignidad humana, igualdad material, justicia social, etc.).

Ahora bien, también esta argumentación tiene sus propias complicaciones, tanto teóricas como prácticas en cuanto a la realización material de dichos derechos vitales. Es decir, además de los conflictos "teóricos" en cuanto a la racionalidad del poder frente a los principios de democracia, de división de poderes y de legalidad; se suman también en el orden real y práctico, que la existencia de ciertas prestaciones positivas que integran el mínimo vital, serán exigibles ante el Poder Judicial (siempre), "independientemente de reglamentación legislativa, previsión

\footnotetext{
38 Wunder Hachem (2014), p. 117.

39 Wunder Hachem (2014), p. 118.

40 Wunder Hachem (2014), p. 118.

41 Es el caso italiano, cuyo Poder Legislativo ha desarrollado su propia versión del derecho al mínimo vital (en un mecanismo pensionístico denominado RMI - Reedito Mínimo de Inserimento-), evitando que la Corte Constitucional tenga alguna injerencia en ese sentido. No existe otra fórmula de mínimos vitales (legales) en alimentación, vestido, vivienda, salud y menos fomentado por la jurisprudencia.

42 Alexy (2008), pp. 46-53.

43 Wunder Hachem (2014), p. 119.
} 
presupuestaria, disponibilidad financiera o existencia de estructura organizacional del Poder público para atenderlas ${ }^{44} "$.

Debe subrayarse, finalmente, que este derecho mínimo/vital aplica tanto para derechos fundamentales como frente a otros derechos que no necesariamente tengan tal calificativo en ciertos sistemas constitucionales (como, por ej., vivienda, alimentación).

\section{De las Relaciones/DifERENCIAS ENTRE LAS CATEgorías INVOLUCRADAS EN LA DETERMINACIÓN DE LOS LÍMITES INTERNOS O MÍNIMOS DE DERECHOS}

Es necesario acá hacer unas pequeñas precisiones. No obstante las diferencias que se encuentran entre las categorías del contenido esencial y el mínimo vital (De Marco ${ }^{45}$ ), algunos autores pueden relacionar en forma homóloga los conceptos de "contenido esencial" y del "derecho o contenido mínimo vital" (García Schwarz ${ }^{46}$ ). En este último caso, también para Lobo -citado por Wunder Hachen- los derechos sociales sólo son fundamentales en relación con su contenido esencial como factor necesario en la garantía del minimo existencial ${ }^{77}$; lo que significa desde ese criterio, que el contenido esencial serviría para ayudar a determinar la garantía del minimo existencial (Sarlet y Agostini ${ }^{48}$ ).

Sin embargo, a pesar de estas relaciones, hay acá algunas diferencias que se predican en la doctrina entre "contenido mínimo" (de todos los derechos en general según la Constitución); "contenido esencial" (establecido principalmente por el legislador) y "contenido del derecho mínimo vital" (que es un derecho fundamental en sí mismo para hacer valer otros derechos "asociados", sean fundamentales o no). En este orden, explica el maestro Nogüeira Alcalá, "todo derecho fundamental asegurado constitucionalmente tiene un contenido mínimo y un contenido esencial, de aplicación directa e inmediata, como asimismo dicho contenido constituye un límite al legislador 49 ". Tal distinción obedece, a que el "contenido esencial" (responde a la tesis basada en los límites "implícitos" al legislador desde

\footnotetext{
44 Wunder Hachem (2014), pp. 121-122.

45 De Marco (2011), p. 249.

46 GARCIA SCHWARZ (2011), p. 87.

47 Wunder Hachem (2014), p. 141.

48 Sarlet, I.W. y Agostini Saavedra, G. (2012), p. 82.

49 Nogueira (2009), p. 156.
} 
la Constitución) frente al "contenido mínimo" (tesis que puede ser consustancial para el establecimiento del derecho al mínimo vital). En esa perspectiva, prosigue el maestro en ese mismo trabajo: "El contenido mínimo de los derechos sociales fundamentales está relacionado con el respeto a la dignidad del ser humano y a la consideración de un mínimo vital que se concreta en cada uno y todos los derechos económicos, sociales y culturales (...)"50. (Resaltado nuestro).

Desde estas relaciones y diferencias entre las categorías que nos ocupan, apreciamos que en cuanto al derecho al mínimo vital, se correspondería con lo que se conoce como el "contenido constitucional mínimo" (implícito o explícito); quedando en este último caso facultado la justicia constitucional para determinarlo (sin esperar desarrollo legal); a distinción del "contenido esencial" (que lo puede establecer - a priori-el legislador) y que sólo llegaría a establecerlo la jurisdicción - a posteriori- en caso de impugnarse tal actuación política del cuerpo legislativo).

Como resultado de estas líneas, valoramos positivamente las relaciones existentes entre las fórmulas que desempeñan el "contenido o derecho mínimo vital" en auxilio al "contenido esencial"; y viceversa; que lejos de enfrentarse, se complementan entre sí. Ambas tienen su propia naturaleza y espacio. Obviamente, en orden de este artículo, hacemos énfasis en la defensa del derecho al mínimo vital (categórico) al lucir más completo desde la óptica de la justicia constitucional en comparación al carácter (directivo) del "contenido esencial" - como afirmaba su promotor Haberle ${ }^{51}$. . Como hemos subrayado atrás -siguiendo a Wunder-el contenido o derecho al mínimo vital lo establece la jurisdicción, porque ya se encontraría acotado (deducido) por el propio constituyente permanente y no por el legislador democrático coyuntural. De este punto de vista, el marco constitucional, puede servir más allá que un punto de vista referencial (que esperar las "actuaciones" legislativas).

\section{DE LA EVOLUCIÓN DEL CONTENIDO MÍNIMO VITAL DESDE LA JURISPRUDENCIA MÁS RELEVANTE}

La intensa jurisprudencia de la preocupación de las altas Cortes en materia de derechos sociales ${ }^{52}$ se pone de manifiesto en materia del derecho al mínimo

50 Nogueira (2009), pp. 192-193.

51 Casal Hernández (2010), p. 281.

52 SAGUÉS (2012), pp. 443-461. 
vital. Más allá de Alemania -cuya jurisprudencia es la rectora de todo ese diálogo-, constan desarrollos jurisprudenciales en Colombia y Brasil, especialmente, quienes parecen haber superado (con creces) la propuesta "original" (según la cantidad de fallos y sus formas); y en menor medida por los pares de España ${ }^{53}$, México ${ }^{54}$, Perú 55 , Suiza ${ }^{56}$ y Portugal ${ }^{57}$. Dentro de las equivalencias, guardando las distintas circunstancias que dieron lugar a los pronunciamientos respectivos, téngase presente que en ninguno de estos países las cartas políticas regulaban el derecho fundamental al "mínimo vital"; aunque otros países, por ejemplo, en el caso de Venezuela, la (penosa y desacreditada) Sala Constitucional, desaprovechó la oportunidad de entrar a desarrollar este punto del mínimo vital (atender un reclamo del "salario mínimo vital" en una acción colectiva en contra el Presidente de la República), despachando el asunto por motivos estrictamente procesales ${ }^{58}$. Fuera de este caso siempre excepcional, pasemos ahora a revisar el trabajo de aquellas Cortes que destacan por su trabajo:

\subsection{La experiencia alemana. El origen de esta cuestión}

La creación de esta categoría se debió al trabajo del Tribunal Contencioso Administrativo (secundado luego por el Tribunal Federal), cuando en el fallo BVerGE 1, 159 (160), expuso: “(...) Los lineamientos principales de la Ley Fundamental llevan a interpretar el derecho a la ayuda social en el sentido de que éste impone una obligación jurídica de ayuda al necesitado, y otorga a este último el derecho subjetivo correspondiente ${ }^{59}$ ". Tiempo después, correspondió al Tribunal Constitucional Federal Alemán (TCFA) ampliar este concepto, cuando en sentencia BVerfGE 40, 121 (133) justificó la necesidad de una “(...) ayuda social para aquellos ciudadanos que se encuentran impedidos en su desarrollo personal

\footnotetext{
53 Tribunal Constitucional (España), (2012).

54 Suprema Corte de la Nación (México), (2013).

55 Tribunal Constitucional (Perú), (2004).

56 Tribunal Constitucional (Suiza), (1995).

57 Tribunal Constitucional (Portugal), (2012).

58 Sala Constitucional, Tribunal Supremo de Justicia (Venezuela), (2001).

59 Arango (2005), pp. 49-50.
} 
y social debido a carencias físicas o espirituales. La comunidad estatal tiene en todo caso que asegurarles las condiciones mínimas para una existencia digna ${ }^{60}$ ".

A partir de estos primeros intentos, el TCFA fue formulando más argumentos a favor de lo que se llamará el "contenido mínimo vital" de los derechos fundamentales, cuando en fallo BVerfGE 82, 60 (85), resolvió que el Estado, "está obligado, en caso de necesidad, a asegurar al ciudadano desprovisto de medios mediante el reconocimiento de prestaciones sociales"; y por tanto, no "(...) puede gravar al ciudadano en sus ingresos hasta el nivel de determinado monto -que a continuación será denominado el mínimo vital-”. En ese caso, se asumió que el llamado "mínimo vital" para toda la familia debería ser libre de impuestos, conforme a las obligaciones que surgen del principio Estado social de derecho6 ${ }^{61}$. Por último, entre las cosas por demás de interesantes de tal creación jurisprudencial, es que este país fue también el primero en aceptar al mínimo vital como verdadero derecho fundamental ${ }^{62}$.

\subsection{La tendencia progresista de Colombia. Una Corte Constitucional (bien) activista}

A juzgar por los datos estadísticos que aporta Arango, si "cerca de 1.200 sentencias proferidas anualmente por la Corte Constitucional, el 60\% versan sobre derechos sociales fundamentales, y las tutelas sobre derecho al mínimo vital son concedidas aproximadamente en un $80 \%$ ", entonces, supone un arduo trabajo. La explicación del autor para sostener tal activismo obedece a que: "A diferencia de sociedades 'bien ordenadas', donde las libertades se tienen como prioritarias frente a la igualdad, ya que las necesidades básicas de la población están aseguradas legislativamente, en los países del Tercer Mundo dicha relación se invierte: los derechos sociales son tenidos como más importantes que las libertades públi$\operatorname{cas}^{63 "}$. La práctica en el reconocimiento del mínimo vital que data de 1992 hasta el presente, junto a otras competencias u ejecutorias, lleva a la Corte al lugar de las más prestigiosas del mundo ${ }^{64}$.

60 Arango (2005), pp. 51-52.

61 Arango (2005), pp. 51-52.

62 Rodriguez-Arana (2017), p. 13 (1-35).

63 Arango (2002), p. 115.

64 MezzetTi (2015), p. 458. 
A partir del reconocimiento de las dificultades propias de un país con tantas desigualdades sociales históricas (entre otros, con un conflicto armado de más de 50 años); se plantea en razón de esa complejidad, la relación de los derechos de los ciudadanos, los órganos de representación y el proceso político. Bajo esa lógica: "Esta pérdida de legitimidad de la política que se refleja en sus leyes, intenta a través de la virtualidad constitucional cobrar un dinamismo que en anteriores ocasiones no propició la discusión política ${ }^{65}$ ".

Allí radica el activismo de la Alta Corte, no sin los problemas procedentes de la siempre cuestionada legitimación de la justicia constitucional; tema que, como hemos advertido, desborda los objetivos acá planteados. Para entender la manera en que esta Corte ha logrado consolidar la idea del derecho al mínimo vital en materia de derechos sociales, conviene entender primeramente cómo se asume tal comportamiento frente a la cláusula del Estado social de derecho que predica su fórmula constitucional en el artículo $1^{\circ}$.

Partiendo de las contradicciones propias del "Estado de derecho" frente al "Estado social", dicha Corte desde 1992 viene a justificar (caso C-479. Magistrado ponente: Alejandro Martínez, José Gregorio Hernández): "Si bien la noción del Estado social de derecho gobierna toda la actuación de todos los operadores jurídicos, en el caso que nos ocupa ella está dirigida muy específicamente a la relación del Estado con sus servidores; dentro de él, el poder político está sujeto a un marco axiológico completo, establecido por la Constitución, cuyo fundamento es la dignidad humana ${ }^{66 "}$ " Con ese "telos" valorativo, dice Torres Ávila, la Corte se "involucra en una clara lucha política por el cumplimiento de su deber, pues la Constitución en este sentido se encuentra abiertamente enfrentada a los planes de desarticulación de las funciones del Estado ${ }^{67}$ ". En esa perspectiva, esa Corte interpreta la cláusula Estado social de derecho [como una fórmula llena de contenido] y cuya materialidad deriva de valores y principios que fundan ese Estado ${ }^{68}$.

En tales orígenes, dice Arango: "La Corte reconoce que el legislador tiene una amplia facultad de configuración normativa en materia tributaria, pero advierte que el ejercicio de la misma debe hacerse dentro de los límites constitucionales"; sobre todo al impactar (negativamente) con ciertas decisiones legislativas a las

65 Torres Ávila (2012), p. 107.

66 Torres Ávila (2012), p. 108.

67 Torres Ávila (2012), p. 109.

68 Torres Ávila (2012), p. 117. 
personas que se encuentran en condiciones más desfavorables ${ }^{69}$. La experiencia de la Corte Constitucional permite ir extendiendo el derecho al mínimo vital como "derecho innominado ${ }^{70 "}$, no sólo en las relaciones de trabajo y derivados ${ }^{71}$, sino también en otro tipo de derechos ${ }^{72}$. Así, es que se puede entender los argumentos asumidos sobre el cómo se concretó en su jurisprudencia el derecho fundamental del minimo vital.

\subsection{El caso de Brasil. El activismo de los jueces ordinarios en conjunto al Tribunal Federal}

En ese país latinoamericano, es tanto el ejercicio de la judicatura en pro de la materialización de los derechos fundamentales vitales, que ha suscitado un intenso debate a nivel académico sobre el punto de hasta dónde deberian estar previstos los limites al activismo judicial. Este debate se circunscribe en las tendencias, (i) de los que afirman existe una aplicación sin criterio de la categoría del mínimo existencial en su jurisprudencia, (ii) de quienes niegan la aplicabilidad de demandas sobre derechos subjetivos; (iii) quienes acuerdan otorgar indiscriminadamente tales tutelas ${ }^{73}$.

Frente a quienes promueven la posición en favor de otorgar las mayores tutelas de mínimos vitales en cuanto sea posible, el Supremo Tribunal Federal, en un fallo de la Segunda Sala (también de relatoría del Min. Celso de Mello), razonó que "la reserva de lo posible no puede ser un obstáculo para la satisfacción judicial de las prestaciones abarcadas por el mínimo existencial. El fundamento utilizado para identificar el derecho al mínimo existencial, considerado como una verdadera barrera al argumento de la escasez de recursos, fue el principio de dignidad de la persona humana ${ }^{74 "}$.

69 Arango (2005), p. 215.

70 Lemaitre (2006), p. 232.

71 Henao (2010), p. 24.

72 Lemaitre (2005), pp. 2-3.

73 Wunder HaCHEM (2014), p. 127.

74 Wunder Hachem (2014), p. 130. 
Entre todas las materias, el derecho a la educación ${ }^{75}$ y a la salud sobresalen, pero sobre todo este último ${ }^{76}$, en contraste con algunos países de Europa (como, por ejemplo, el caso de Italia según algunos trabajos comparativos ${ }^{77}$ ). En este inmenso país sudamericano, se divide la opinión respecto del (excesivo) activismo judicial y sus límites (reserva de lo posible, principio de legalidad y separación de poderes, entre otros argumentos), muchas veces superados por la interpretación en favor de las tutelas demandadas ${ }^{78}$.

Pero además de la posición asumida por el Supremo Tribunal, en el caso brasileño es paradigmático -y significativo- el trabajo de los jueces ordinarios en razón de las cantidades de casos resueltos en tutelas concedidas, forzando los límites convencionales en materia de los derechos sociales (de hasta dónde pueden al implicarse en temas tan complejos como los presupuestarios al condenar a importantes erogaciones estatales), tema que se complica en una economía cuando tiene grandes defectos estructurales.

\section{Conclusiones (preliminares, jamás definitivas)}

Este diálogo promovido por la doctrina para "conectar" ciertas categorías que son comunes entre sí y su correspondiente apoyo por la jurisprudencia, cuenta ahora con un nuevo impulso. Pues, en el mismo momento en que planteamos la articulación de Cortes en forma de diálogo (y no monólogo), existe un evidente liderazgo de la región latinoamericana al sumar a este debate, la reciente propuesta del derecho al mínimo vital como derecho humano por parte de la Corte Interamericana en Derechos Humanos (CIDH), cuando en Opinión Consultiva ha venido propiciando el reconocimiento de un derecho al mínimo vital, "cuyo concepto está atado al principio de la dignidad (artículo 11 de la Convención Americana), correspondiente a las necesidades más básicas y esenciales de la persona y de su familia" (CIDH, Opinión Consultiva OC-22, 26 de febrero 2017). Se trata, pues, de un incipiente, pero interesante apoyo que puede dar mejores resultados, si se entiende la presencia de un verdadero diálogo en otras materias

\footnotetext{
75 Wunder HaChem (2014), p. 129.

76 Sariet, I. y Figueiredo, M. (2007), pp. 171 y ss.

7 Barbosa (2017), pp. 109-130.

78 Wunder Hachem (2014), p. 127.
} 
desde varias direcciones ${ }^{79}$, bien entre la propia CIDH y el resto de tribunales regionales, bien entre otras Cortes en DDHH (de Europa y África).

En consecuencia, a modo de resumen se presentan unas breves conclusiones, jamás completas, nunca finales:

1. En la determinación de los contenidos (mínimos) de derechos sociales fundamentales convergen varias teorías, entre las que destaca -en orden a su importancia práctica-, el "contenido esencial" y "contenido o derecho al mínimo vital/existencial".

2. Que tanto el "contenido esencial" como el "derecho al mínimo vital" nacen primero desde sus respectivos aportes desde la doctrina, con vocación de ciencia jurídica. En ambos casos, se requiere la presencia de la justicia constitucional en pro de cada uno de sus objetivos.

3. Que la "teoría del contenido esencial" (que ha sido receptada por diversas Cartas Constitucionales) fue prevista para evitar el vaciamiento de los contenidos constitucionales en virtud de las actuaciones del legislador.

4. Que la "teoría del derecho al mínimo vital" (que no encuentra recepción en alguna Constitución "expresamente") fue prevista para darle contenido real a los contenidos constitucionales (implícitos) y aplica (i) tanto frente a las omisiones legislativas, (ii) como frente a ciertas actividades legislativas.

5. Que respecto a la teoría del derecho al mínimo vital la relación con el Poder Legislativo, no es -como en el caso del contenido esencial- para evitar la limitación de los derechos (desarrollados legislativamente), sino más bien, para exigir el cumplimiento de otros no desarrollados o desarrollados indebidamente.

6. Que alguna doctrina encuentra puntos de conexión (en forma de homologación) entre el contenido esencial y el contenido mínimo vital y otras en forma diferenciada, pero que, en todo caso, lucen complementarias.

7. Que existe un verdadero diálogo entre Cortes cuando determinados tribunales europeos y americanos han establecido canales de comunicación para desarrollar interesantes precedentes en materia de contenidos esenciales y de contenidos mínimos existenciales o vitales.

8. Que si bien la doctrina alemana y su jurisprudencia han creado todo un movimiento en favor del activismo judicial frente al reconocimiento del llamado derecho fundamental al mínimo vital; apoyado después con un Poder Legislativo consciente en su labor de actualizar sus contenidos; otros países se han unido a esa

79 Cfr., Garcia Roca (2017), pp. 205 y ss. 
tendencia (por Europa: España, Suiza y Portugal; por América: Colombia, Brasil, México y Perú). Que no obstante aquellos orígenes, están Colombia y Brasil a la cabeza en donde existe un movimiento de amplísimo activismo judicial en esta materia que supera la propuesta originaria.

9. Que el diálogo entre doctrina, Constitución y jurisprudencia hace posible una nueva etapa de la justicia constitucional; y que puede ser aún más rica que la forma en que colaboran entre sí (bidireccionalmente y retroalimentándose), los tribunales de derechos regionales de derechos humanos americano y europeo; sobre todo, cuando ya existen ciertas aproximaciones por parte de la Corte Interamericana de Derechos Humanos en este sentido en Opinión Consultiva.

10. Que la categoría regional americana del "derecho a condiciones de existencia dignas" 80 , se nos parecen mucho (en su argumentación) al "derecho al mínimo vital", como bien se viene infiriendo. Según parece, las categorías del "contenido esencial", del "derecho al mínimo vital" y el "derecho a condiciones de existencia digna" se vienen acercando cada vez más en la difícil materialidad de los derechos sociales fundamentales.

En fin, seguimos la tendencia que como Landa pone de manifiesto acerca de la importancia que adquiere la justicia constitucional en su "rol subsidiario como (re)creador de los derechos sociales que la Constitución consagra ${ }^{81}$ ”. Más que un juego de palabras - parafraseando al autor--, el legislador crea derechos, la Constitución ya los contiene y la justicia constitucional (sólo) los recrea en distintas formas, como sucede en el caso de la indicada categoría del derecho al mínimo vital.

\section{BIBLIOGRAFÍA CITADA}

Abramovich, Víctor y Courtis, Christian (2006): El umbral de la ciudadanía. El significado de los derechos sociales en el estado social (Buenos Aires, Argentina, Ed. Estudios del Puerto).

AleXY, Robert (2008): La Teoría de los Derechos Fundamentales. 2a edición (Madrid, Centro de Estudios Políticos y Constitucionales).

Arango, Rodolfo (2002): "Promoción de los derechos sociales constitucionales por vía de protección judicial”, en: El Otro Derecho, (núm. 28, julio), (Bogotá D.C., Colombia., Ed. Ilsa).

80 Belof y Clérico (2017), p. 142.

81 LANDA (2012), p. 241. 
Arango, Rodolfo (2005): El concepto de derechos sociales fundamentales, Universidad Nacional de Colombia, 1a ed., Bogotá, (Colombia Ed. Legis).

Balaguer Callejón, Francisco (2001): "Capacidad creativa y límites del legislador en relación a los derechos fundamentales. La garantía del contenido esencial de los derechos", en: Derechos Constitucionales y formas politicas. Actas del congreso sobre derechos constitucionales y Estado autonómico, Estudios constitucionales y políticos, M. Á. Aparicio (Coord.), (Barcelona, España, Cedecs Ed.).

Barbosa, Elina Magnan (2017): "Diritto a la salute. Evoluzione della giurisprudenza costituzionale in Brasile e in Italia”, en: La tutela dei diritti fondamentali attraverso le Esperienze dei paesi di provenienza di alcuni dei partecipanti al corso di alta formazione in Giustizia costituzionale e tutela giurisdizionale dei diritti, A cura di G. Famiglietti e R. Romboli, Corso di Alta formazione in Giustizia Costituzionale e tutela giurisdizionale dei diritti, (Pisa, Italia, Università di Pisa, University Press).

Belof, Mary y Clérico, Laura (2017): 'Derecho a condiciones de existencia digna y situación de vulnerabilidad en la jurisprudencia de la Corte Interamericana", Revista del Centro de Estudios de Derecho Constitucional de Chile, Universidad de Talca, (Año 14, No 1). [Disponible:https://drive.google.com/ file/d/0B4415pHYhRzaakZ0bThDZTctYnc/view] [Fecha de la consulta: diciembre, 2017].

Bernal Pulido, Carlos (2008): "Fundamento, conceito e estrutura dos direitos sociais: uma crítica a 'Existem direitos sociais?' de Fernando Atria”. Direitos sociais: fundamentos, judicializaçâo e direitos sociais em espécie, C. Pereira de Souza Neto y D. Sarmento (Coords.), (Rio de Janeiro, Brasil, Ed. Lumen Juris).

Carbonell, Miguel (2007): Neoconstitucionalismo y derechos fundamentales, (Buenos Aires, Argentina, Ed. Ad-hoc.)

Carmona Cuenca, Encarnación (2012): "El derecho a un mínimo vital con especial referencia a la Constitución española de 1978", Estudios Internacionales, (No 172), (Chile, Universidad de Chile, Instituto de Estudios Internacionales). [Fecha de la consulta: marzo, 2015]. [Disponible: file://C:/Users/VISTA/ Downloads/23587-92112-1-PB.pdf].

Casal Hernández, Jesús M. (2010): Los derechos fundamentales y sus restricciones. $1^{a}$ ed., (Caracas, Venezuela, Ed. Legis).

Cossio, José Ramón (1989): Estado social y derechos de prestación, (Madrid, España, Centro de Estudios Constitucionales).

Cruz Villalón, Pedro (1989): "Formación y evolución de los Derechos fundamentales", Revista Española de Derecho constitucional (año 9, núm. 25), ene- 
abr., Madrid, España. [Fecha de consulta: febrero, 2015]. [Disponible: file://C:/ Users/Michelle/Downloads/Dialnet-FormacionYEvolucionDeLosDerechosFundamentales-79388.pdf].

De Barcellos, Ana Paula (2008): "O direito a prestações de saúde: complexidades, mínimo existencial e o valor das abordagens coletiva e abstrata”. In: Cláudio Pereira de Souza Neto; Daniel Sarmento (Coords.). Direitos sociais: fundamentos, judicialização e direitos sociais em espécie, (Rio de Janeiro, Brasil, Ed. Lumen Juris).

De Marco, Cristhian Magnus (2011): "Elementos sobre a autonomía privada e sua relação com o mínimo existencial na teoria dos direitos fundamentais", en: A realização e a proteção internacional dos direitos humanos fundamentais. Desafios do século XXI, Organizadores: Nerciso Leandro Xavier Baez y Douglas Cassel, Fundación para el debido proceso (Joaçaba, Brasil, Editora Unoesc).

GARCía SCHWARZ, Rodrigo (2011): Los derechos sociales como derechos humanos fundamentales. Su imprescindibilidady sus garantías, Serie El Derecho (Ciudad de México, México, Ed. Miguel Ángel Porrúa).

García Roca, Javier (2017): "El diálogo sobre derechos humanos entre el Tribunal Europeo y la Corte Interamericana", en: Memorias del IV Congreso Internacional de Derecho Procesal Constitucional y IV en Derecho Administrativo, Homenaje al Dr. Carlos Ayala Corao, Universidad Monteávila, (Caracas, Venezuela, Editorial Jurídica Venezolana).

Henao Hidrón, Javier (2010): Derecho procesal Constitucional, $3^{a}$ ed., (Bogotá, Ed. Temis).

Landa, César (2012). "Los derechos sociales en la jurisprudencia constitucional de América Latina”, diciembre (No 45), (Perú, Revista Ius et Veritas). [Fecha de consulta: noviembre, 2017]. [Disponible: file://C:/Users/Michelle/ Downloads/12000-47749-1-PB.pdf].

LEMAITRE RIPOLL, Julieta (2005): El coronel sí tiene quien le escriba: la tutela por minimo vital en Colombia, Yale Law School Yale Law School Legal, Scholarship Repository SELA (EE.UU., Seminario en Latinoamérica de Teoría Constitucional y Política), [Fecha de consulta: diciembre, 2017]. [Disponible: http://digitalcommons.law.yale.edu/cgi/viewcontent.cgi?article=1042\&context=yls_sela].

Lemaitre Ripoll, Julieta (2006): "Alcances de la reforma legal. De la prohibición de despido de la mujer embarazada en Colombia”, en AA.VV., Más allá del derecho. Justicia y género en América Latina, L. Cabal y C. Motta, Siglo del Hombre Editores, Red Alas, Colección Equidad y Justicia (Bogotá, Universidad de Los Andes). 
Löthar, Michael (2009): “¿El contenido esencial como común denominador de los derechos fundamentales en Europa?", Revista de Derecho Constitucional europeo, (año 6, No 11), ene-jun. [Fecha de consulta: febrero, 2015]. [Disponible: http://www.ugr.es/-redce/REDCE11pdf/06_LOTHAR\%20MICHAEL.pdf].

López Ulla, Juan M. (2014): "Derecho Comparado y justicia constitucional”, en: Justicia constitucional comparada, Biblioteca Porrúa de Derecho Procesal Constitucional, Silvia Bagni (Coord.), (No 106), (Ciudad de México, México, Ed. Porrúa).

Mezzetti, Luca (2015): "La protección de los derechos sociales. Entre cortes constitucionales nacionales y cortes supranacionales", en: Derecho Frocesal Constitucional (Obra colectiva), E. Velandia Canosa (Dir.), (Bogotá, Colombia, Universidad Santo Tomás, Ed. Legis).

Nogueira Alcalá, Humberto (2009): "Los derechos económicos, sociales y culturales como derechos fundamentales efectivos en el constitucionalismo democrático latinoamericano". Estudios Constitucionales, Universidad de Talca (vol. 7, núm. 2). (Santiago de Chile, Centro de Estudios Constitucionales de Chile). [Fecha de consulta: octubre, 2015]. [Disponible: http://docplayer.es/10886519Los-derechos-economicos-sociales-y-culturales-como-derechos-fundamentalesefectivos-en-el-constitucionalismo-democratico-latinoamericano.html].

Nogueira Alcalá, Humberto (2003): Teoría y dogmática de los derechos fundamentales, Instituto de Investigaciones Jurídicas, serie Doctrina Jurídica, (No 156), (Ciudad de México, Ed. UNAM). [Fecha de consulta: febrero, 2014][Disponible: http://biblio.juridicas.unam.mx/libros/3/1094/13.pdf].

Obando Blanco, Víctor R. (2002): El derecho a la tutela jurisdiccional, Serie Derechos y Garantías, (No 1), 2a ed., (Lima, Perú, Palestra Editores).

Petit Guerra, Luis (2012): "El derecho legislativo y el derecho judicial en el sistema de fuentes y el control democrático", AA.VV., Direitos Fundamentais da pessoa humana. Um diálogo latino-americano, cap. II (Curitiba, Brasil, Editora Alteridade).

Rodríguez-Arana, Jaime (2017): "Sobre el concepto de los derechos sociales fundamentales", Revista Digital, Asociación Argentina de Derecho Administrativo, No 1. [Disponible: file://C:/Users/Michelle/Downloads/6050-16453-1-PB.pdf] [Fecha de consulta: enero, 2017].

SaGÜÉs, Néstor Pedro (2017): La Constitución bajo tensión, Constitución y democracia, $1^{\text {a }}$ ed., (México, Instituto de Estudios Constitucionales del Estado de Querétaro). 
SAGÜÉs, Néstor Pedro (2012): "Los tribunales constitucionales como agentes de cambios sociales", en: Direitos Fundamentais Da Pessoa Humana. Um Diálogo Latino-Americano (Curitiba, Brasil, Editora Alteridade).

SARLET, Ingo Wolfang (2015): Dignidad (de la persona) humana, minimo existencial y justicia constitucional. Algunas aproximaciones y algunos desafios, Biblioteca jurídica virtual del Instituto de Investigaciones Jurídicas, (Ciudad de México, Ed. UNAM). [Fecha de consulta: febrero, 2015]. [Disponible: http://biblio.juridicas. unam.mx/libros/8/3977/29.pdf].

Sarlet, Ingo y Agostini SaAvedra, Giovani (2012): "Breves notas sobre a garantia do mínimo existencial e os limites materiais de atuaçāo do legislador, com destaque para o caso da Alemanha”, en: Direitos Fundamentais da pessoa humana. Um diálogo latino-americano, (Curitiba, Brasil, Ed. Alteridade).

Sarlet, Ingo S. y Figueiredo, Mariana (2007): Reserva de Possivel, Minimo Existencial e o Direito à Saúde: algumas aproximaçōes. Direitos Fundamentais \& Justiça, (No 1), (Porto Alegre, Brasil, Livraria do Advogado).

STERN, Klaus (1998): "El sistema de los derechos fundamentales en la República Federal de Alemania", (No 1), (Madrid, España, Revista del Centro de Estudios Constitucionales). [Fecha de consulta: enero, 2014]. [Disponible: file://C:/Users/ Michelle/Downloads/Dialnet-ElSistemaDeLosDerechosFundamentalesEnLaRepublicaFe-1048054.pdf].

Tenorio, Pedro (2012): "El Tribunal Constitucional, la cláusula Estado social, los derechos sociales y el derecho a un mínimo vital digno", cap. 12, en: Derechos sociales y principios rectores, Actas del IX Congreso de la Asociación de Constitucionalistas de España (celebrado en Santa Cruz de Tenerife, enero 2011), J. L. Cascajo Castro, M. Terol Becerra, A. Domínguez Vila, V. Navarro Marchante (Coords.), (Valencia, España, Ed. Tirant Lo Blanch).

Tisseau, Guillaume (2014): "Más allá de los modelos de justicia constitucional, hacia una comparación pragmatista", en: Justicia constitucional comparada, Biblioteca Porrúa de Derecho Procesal Constitucional, Silvia Bagni (Coord.), (No 106), (Ciudad de México, México, Ed. Porrúa).

Torres Ávila, Jheison (2012): El mandato del Estado social de derecho en la Constitución colombiana: los derechos sociales y el minimo vital, (Bogotá, Colombia, Ed. Universidad Santo Tomás).

Varas, Paulino y Mohor, Salvador (1997): "Acerca de la esencia de los derechos constitucionales y de su libre ejercicio que consagra el artículo 19 No 26 de la Constitución Política”, (n. XVIII) (Valparaíso, Chile, Revista de Derecho de la 
Universidad de Valparaíso). Disponible: http://www.rdpucv.cl/index.php/rderecho/ article/viewFile/363/338. [Fecha de consulta: marzo, 2015].

VON BernstorfF, Jochen (2011): "Protección del contenido esencial de los derechos humanos", en: Construcción y papel de los derechos sociales fundamentales. Hacia un Ius Constitucionale Commune en América Latina, A. Von Bogdandy, H. Fix-Fierro, M. Morales Antoniazzi, E. Ferrer Mac-Gregor (Coords.), Instituto de Investigaciones Jurídicas Max-Planck, Instituto Iberoamericano de Derecho Constitucional, Instituto de Investigaciones Jurídicas, Serie Doctrina Jurídica, (No 615), (Ciudad México, México, UNAM).

Wunder Hachem, Daniel (2014): "Mínimo existencial y derechos económicos y sociales: distinciones y puntos de contacto a la luz de la doctrina y jurisprudencia brasileñas", Revista Eurolatinoamericana de Derecho Administrativo, (No 1, vol.1), (Santa Fe, Argentina, Universidad Nacional del Litoral). [Fecha de la consulta: enero, 2017]. [Disponible: http://bibliotecavirtual.unl.edu.ar/ojs/index.php/ Redoeda/article/view/4609/7036].

\section{JURISPRUDENCIA CITADA}

Tribunal Constitucional (Perú), Exp. No 1417-2005-AA, Fj. 34 y 37. Recurso de agravio constitucional interpuesto por don Manuel Anicama Hernández, contra la sentencia de la Cuarta Sala Civil de la Corte Superior de Justicia de Lima, de fojas 148, su fecha 6 de octubre de 2004, que declaró improcedente la demanda de amparo de autos.

Tribunal Constitucional (Perú). Exp. No 02246-2012-pa/tc, Loreto, Gobierno Regional de Loreto. [Fecha de consulta: marzo, 2017]. [Disponible:http://www. tc.gob.pe/jurisprudencia/2012/02246-2012-AA\%20Resolucion.html].

Tribunal Constitucional (Suiza), Schweizerisches Bundesgericht (Bger) Lausanne, II. Öffentliche Abteilung, 29. September 1995, EuGH 1996.

Tribunal Constitucional (Portugal), Acórdão No 509/2012, Processo No 615/12, 1a Secção. Relatora: Processo No 615/12, Relatora: Conselheira Maria Joāo Antunes. Asunto: Ministerio Público en recurso al abrigo de la línea b) del número 1 del artículo 70 de la Ley de Organización, funcionamiento y proceso del Tribunal Constitucional (LTC), en contra del fallo del 2 de mayo de 2012, expedido por el Tribunal de Relación de Porto.

Tribunal Constitucional (España), No 3534, Pleno, Sentencia 19/2012, de 15 de febrero de 2012. Asunto: Recurso de inconstitucionalidad 1046-1999 planteado por 89 diputados del Grupo Parlamentario Socialista en el Congreso contra los 
arts. $2.2,15.1,15.3 .4,17.2$ c) y d), 24.2 b) y c), 39, 40, 43.2 f), 44.1.1 a), 48, $51,53,58,60,61,62,63,64,81.1,2$ y 3 , y disposiciones transitorias cuarta, quinta apartado 2, sexta y séptima, de la ley 40/1998, de 9 de diciembre, del impuesto sobre la renta de las personas físicas y otras normas tributarias. [Fecha de la consulta febrero, 2015]. [Disponible: http://hj.tribunalconstitucional.es/ $\mathrm{HJ} / \mathrm{docs} / \mathrm{BOE} / \mathrm{BOE}-\mathrm{A}-2012-3534 . \mathrm{pdf}]$.

Sala Constitucional, Tribunal Supremo de Justicia (Venezuela), sentencia 1369/2001, del 3 de agosto. [Fecha de consulta: febrero, 2015]. [Disponible: http://historico.tsj.gOb. Cit.ve/decisiones/scon/agosto/1369-030801-01-0990. HTM].

Sala Constitucional, Corte Suprema de Justicia (Costa Rica), (1999), Acción Inconstitucional Voto 7660-99 Exp.: 99-003312-0007-CO Res.: 1999-07660 [Fecha de consulta: marzo, 2017]. [Disponible en: http:/www.acnur.org/t3/ fileadmin/Documentos/BDL/2012/3164.pdf?view=1].

Sala Político Administrativa, Corte Suprema de Justicia (CSJ) (1997), caso Tiuna Tours, C.A., 19 de junio de 1997.

Suprema Corte de la Nación (2013), Semanario Judicial de la Federación, 159820, [Fecha de consulta: marzo, 2017]. [Disponible en: http://200.38.163.178/ SJFSist/(F(YtokM3CLa-01Ats8_kJwNn8EUCzSlc819OvTvu2EZBxqFVV9SKwOLjR2hdovk9ki8NuMDRp98hdV3FsDgJtTGnHTJeGN3BC6QPUTJq2DPwKO1LMCmehwsnH1fqyFIdaXIJH_Kf1f5zNq_cfjOZ9gu-z5OHBSij5VUnn_vDv94E1))/Paginas/DetalleGeneralV2 .aspx?id=159820\&Clase=De talleTesisBL]. 